Pacific Journal of Mathematics

SUFFICIENCY OF JETS 


\title{
SUFFICIENCY OF JETS
}

\author{
JEAN-JACQUES GeRVAIS
}

We give a necessary and sufficient condition for the $C^{\infty}$ sufficiency of a jet: this generalizes and improves some results of J. N. Mather and J. C. Tougeron. Our result, given in terms of $G$-sufficiency which is a generalization of the ordinary sufficiency, can be applied to many cases.

Notations. Let $G$ be a $q$-dimensional Lie subgroup of $G l_{p}(\boldsymbol{R})$. Let $G(n)=C_{0, e}^{\infty}\left(\boldsymbol{R}^{n}, G\right)$ be the group of germs at 0 of smooth mappings $g$ from $\boldsymbol{R}^{n}$ to $G$ such that $g(0)=e$ (where $e$ is the identity of $G$ ) and $\operatorname{Diff}(n)$ the group of germs at 0 of smooth diffeomorphisms $\tau$ from a neighborhood of 0 in $\boldsymbol{R}^{n}$ on a neighborhood of 0 in $\boldsymbol{R}^{n}$ such that $\tau(0)=0$. Let $\mathscr{E}_{n}$ be the ring of germs at 0 of smooth functions from $\boldsymbol{R}^{n}$ to $\boldsymbol{R}$ and $m$ its maximal ideal. For $f \in \bigoplus_{p} m$, $j^{r}(f)$ will denote the $r$-jet of $f$ at 0 . The set $\mathscr{G}(n)=G(n) \times$ $\operatorname{Diff}(n)$ is a group with the following multiplication: $\left(g_{1}, \tau_{1}\right) \cdot\left(g_{2}, \tau_{2}\right)=$ $\left(g_{1} \cdot\left(g_{2} \circ \tau_{1}^{-1}\right), \tau_{1} \circ \tau_{2}\right)$. Then we may define an action of $\mathscr{G}(n)$ on $\bigoplus_{p} m$ by the formula: for $(g, \tau) \in \mathscr{G}(n)$ and $f \in \bigoplus_{p} m,(g, \tau) \cdot f$ is the germ at 0 of the mapping $x \mapsto \widetilde{g}(x) \cdot\left(\tilde{f} \circ \widetilde{\tau}^{-1}(X)\right)$ where $\widetilde{g}, \widetilde{f}$, and $\widetilde{\tau}$ are representatives of $g, f$, and $\tau$ respectively.

Definition 1. An $r$-jet $z$ of an element of $\bigoplus_{p} m$ is $G$-sufficient if for any $f \in \bigoplus_{p} m$ such that $j^{r}(f)=z$ there exists $(g, \tau) \in \mathscr{G}(n)$ such that $(g, \tau) \cdot f=z$.

REMARK. When $G=\{e\}$ and $p=1$ the $G$-sufficiency is the ordinary $C^{\infty}$-sufficiency of jets.

We will use the well known:

Nakayama's Lemma. Let $A$ be a commutative ring with identity and let $I$ be an ideal in $A$ such that $1+a$ is invertible for any $a \in I$. Let $M$ and $N$ be submodules of an $A$-module $P$ such that $M$ is finitely generated and $M \subset N+I . M$. Then $M \subset N$.

Jets $G$-sufficient. Let $\left\{A_{1}, \cdots, A_{q}\right\}$ be a base over $\boldsymbol{R}$ of the Lie algebra $T_{e} G$ of $G$. For every $g \in G(n)$ there exists $u=\left(u_{1}, \cdots, u_{q}\right) \in$ $\oplus_{q} m$ such that

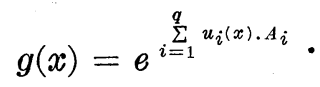


Hence we may identify $G(n)$ with $\bigoplus_{q} m$.

Let $\mathscr{G}^{r}$ be the analytic Lie group of the $r$-jets of the elements of $\mathscr{G}(n)$ and let $X^{r}$ be the space of $r$-jets of the elements of $\bigoplus_{p} m$. The group action of $\mathscr{G}(n)$ on $\bigoplus_{p} m$ induces, for each $r$, a well defined group action of $\mathscr{G}^{r}$ on $X^{r}$. One easily sees that this group action is analytic for each $r$.

For $f \in \bigoplus_{p} m$, let $M_{f}$ be the $\mathscr{E}_{n}$-linear mapping:

$$
M_{f}: \mathscr{E}_{n}^{p+q} \longrightarrow \mathscr{E}_{n}^{p},
$$

where $M_{f}$ is given by the $p \times(q+n)$-matrix with $A_{1} \cdot f, \cdots, A_{q} \cdot f$, $\partial f / \partial x_{1}, \cdots, \partial f / \partial x_{n}$ as columns. It is easily seen that for $f \in \bigoplus_{p} m$ the mapping

$$
\bar{M}_{f}^{r}: \bigoplus_{q+n}\left(\frac{m}{m^{r+1}}\right) \longrightarrow \bigoplus_{p}\left(\frac{m}{m^{r+1}}\right),
$$

derived from $M_{f}$, is the tangent mapping at the idendity of the mapping

$$
\mathscr{G}^{r} \ni \gamma \longrightarrow \gamma \cdot j^{r}(f) \in X^{r}
$$

THEOREM 1. Let $z \in X^{r}$. The following statements are equivalent:

(i) $z$ is G-sufficient.

(ii) For any homogeneous jet $w$ of degree $r+1$ we have $m \cdot \operatorname{Im} M_{z+w} \supset m^{r+1} \cdot \mathscr{C}_{n}^{p}$ (where $\operatorname{Im} M_{z+w}$ is the range of $M_{z+w}$ ).

Proof.

(i) $\Rightarrow$ (ii) Let $w$ and $w^{\prime}$ be two homogeneous jets of degree $r+1$. Since $z$ is $G$-sufficient, there exist $(g, \tau)$ and $\left(g^{\prime}, \tau^{\prime}\right) \in \mathscr{G}(n)$ such that $(g, \tau) \cdot z=z+w$ and $\left(g^{\prime}, \tau^{\prime}\right) \cdot z=z+w^{\prime}$; hence $\left(g^{\prime}, \tau^{\prime}\right) \cdot(g, \tau)^{-1} \cdot(z+w)=$ $z+w^{\prime}$.

Consequently, if we put $\gamma=j^{r+1}\left(\left(g^{\prime}, \tau^{\prime}\right) \cdot(g, \tau)^{-1}\right)$, we have $\gamma \cdot(z+w)=z+w^{\prime}$. We have thus shown that for any homogeneous jet $w$ of degree $r+1$ the $\mathscr{G}^{r+1}$ orbit of $z+w$ in $X^{r+1}$ contains $\left\{z+w^{\prime} \mid w^{\prime}\right.$ is a homogeneous jet of degree $\left.r+1\right\}$. Since the tangent mapping at the identity of the mapping $\mathscr{G}^{r+1} \ni \gamma \mapsto \gamma \cdot(z+w) \epsilon$ $X^{r+1}$ is

$$
\overline{M_{z+w}^{r+1}}: \bigoplus_{q+n}\left(\frac{m}{m^{r+2}}\right) \longrightarrow \bigoplus_{p}\left(\frac{m}{m^{r+2}}\right),
$$

derived from $M_{z+w}$, we have $\operatorname{Im} \overline{M_{z+w}^{r+1}} \supset \bigoplus_{p}\left(m^{r+1} / m^{r+2}\right)$, i.e., $m \cdot \operatorname{Im} M_{z+w}+m^{r+2} \cdot \mathscr{E}_{n}^{p} \supset m^{r+1} \cdot \mathscr{E}_{n}^{p}$. From the Nakayama's lemma, we 
conclude that $m \cdot \operatorname{Im} M_{z+w} \supset m^{r+1} \cdot \mathscr{C}_{n}^{p}$.

(ii) $\Rightarrow$ (i)

(a) Let $w_{1}, \cdots, w_{k}$ be homogeneous jets of degree $r+1, \cdots, r+k$ respectively and put $z^{\prime}=\sum_{i=1}^{k} w_{i}$. Let $t_{0} \in[0,1]$. By hypothesis,

$$
m \cdot \operatorname{Im} M_{z+t_{0} w_{1}} \supset m^{r+1} \cdot \mathscr{E}_{n}^{p} .
$$

Hence we have

$$
m^{r+1} \cdot \mathscr{C}_{n}^{p} \subset m \cdot \operatorname{Im} M_{z+t_{0} w_{1}} \subset m \cdot \operatorname{Im} M_{z+t_{0} z^{\prime}}+m^{r+2} \cdot \mathscr{C}_{n}^{p} .
$$

Nakayama's lemma implies

$$
m^{r+1} \cdot \mathscr{E}_{n}^{p} \subset m \cdot \operatorname{Im} M_{z+t_{0} z^{\prime}} \cdot
$$

Then the range of the mapping $\mathscr{G}^{r+k} \ni \gamma \mapsto \gamma \cdot\left(z+t_{0} z^{\prime}\right)$ contains all $r+k$-jets $z+z^{\prime \prime}$, where $z^{\prime \prime}$ is an $r+k$-jet in a neighborhood of $t_{0} z^{\prime}$ such that $j^{r}\left(z^{\prime \prime}\right)=0$. In particular, there exist $t_{1}<t_{0}<t_{2}$ such that for all $t^{\prime}$ and $t^{\prime \prime} \in\left[t_{1}, t_{2}\right]$, there exists $(g, \tau) \in \mathscr{G}(n)$ such that $j^{s+k}\left((g, \tau) \cdot\left(z+t^{\prime} z^{\prime}\right)\right)=z+t^{\prime \prime} z^{\prime}$. Since $[0,1]$ is compact, it follows that there exists $(g, \tau) \in \mathscr{G}(n)$ such that $j^{s+k}\left((g, \tau) \cdot\left(z+z^{\prime}\right)\right)=$ $z+0 \cdot z^{\prime}=z$.

(b) Let $f \in \bigoplus_{p} m$ such that $j^{r}(f)=z$, we must prove that there exists $(g, \tau) \in \mathscr{G}(n)$ such that $(g, \tau) \cdot f=z$. We have

Hence

$$
m^{r+1} \cdot \mathscr{E}_{n}^{p} \subset m \cdot \operatorname{Im} M_{j^{r+1}(f)} .
$$

$$
m^{r+1} \cdot \mathscr{E}_{n}^{p} \subset m \cdot \operatorname{Im} M_{j^{r+1}(f)} \subset m \cdot \operatorname{Im} M_{f}+m^{r+2} \cdot \mathscr{E}_{n}^{p} .
$$

Nakayama's lemma implies

$$
m^{r+1} \cdot \mathscr{E}_{n}^{p} \subset m \cdot \operatorname{Im} M_{f} .
$$

It follows from a result of J. C. Tougeron [2, Théorème VIII 3.6] that there exists $N \in N$ such that $j^{N}(f)$ is $G$-sufficient. If $N \leqq r$ the proof is finished. Suppose $N>r$. By(a), there exist $\left(g_{1}, \tau_{1}\right) \in$ $\mathscr{G}(n)$ and $\phi \in m^{N+1} \cdot \mathscr{E}_{n}^{p}$ such that

$$
\begin{aligned}
& z=\left(g_{1}, \tau_{1}\right) \cdot j^{N}(f)+\phi ; \text { hence } \\
& z=\left(g_{1}, \tau_{1}\right) \cdot\left[j^{N}(f)+\left(g_{1}, \tau_{1}\right)^{-1} \cdot \phi\right] .
\end{aligned}
$$

Since $\phi \in m^{N+1} \cdot \mathscr{E}_{n}^{p},\left(g_{1}, \tau_{1}\right)^{-1} \cdot \phi \in m^{N+1} \cdot \mathscr{E}_{n}^{p}$. But $j^{N}(f)$ is $G$-sufficient, consequently there exists $\left(g_{2}, \tau_{2}\right) \in \mathscr{G}(n)$ such that

Hence

$$
j^{N}(f)+\left(g_{1}, \tau_{1}\right)^{-1} \cdot \phi=\left(g_{2}, \tau_{2}\right) \cdot f .
$$




$$
z=\left(g_{1}, \tau_{1}\right) \cdot\left(g_{2}, \tau_{2}\right) \cdot f
$$

Definition 2. Let $f \in m$. We say that $f$ is $r$-determined if $j^{r}(f)$ is $C^{\infty}$-sufficient (i.e., $G$-sufficient with $G=\{e\}$ ).

From Theorem 1 we deduce the following two results of J. N. Mather [1], stated as follows in [3, Theorem 2.6 and Corollary 2.10]:

THEOREM 2. Let $f \in m$ and $I_{f}$ be the ideal generated in $\mathscr{E}_{n}$ by the partial derivatives of $f$. If

$$
m^{r} \subset m \cdot I_{f}+m^{r+1},
$$

then $f$ is r-determined.

Theorem 3. Let $f \in m$ be r-determined. Then

$$
m^{r+1} \subset m \cdot I_{f} \text {. }
$$

\section{REFERENCES}

1. J. N. Mather, Stability of $C^{\infty}$ mappings: III Finitely determined map-germs, Publ. Math. IHES, 35 (1968), 127-156.

2. J. C. Tougeron, Idéaux de Fonctions Différentiables, Ergebnisse Band 71, SpringerVerlag, New York, 1972.

3. G. Wassermann, Stability of Unfoldings, Springer Lectures Notes 393, New York, 1974.

Received February 10, 1977.

UNIVERSITÉ LAVAL

QUEBEC, G1K 7P4, CANADA 


\title{
PACIFIC JOURNAL OF MATHEMATICS
}

\section{EDITORS}

\author{
RICHARD ARENS (Managing Editor) \\ University of California \\ Los Angeles, CA 90024 \\ Charles W. Curtis \\ University of Oregon \\ Eugene, OR 97403 \\ C. C. MOORE \\ University of California \\ Berkeley, CA 94720
}

\section{J. DUGUNDJI}

Department of Mathematics

University of Southern California

Los Angeles, CA 90007

R. FINN and J. MILGRAM

Stanford University

Stanford, CA 94305

\section{ASSOCIATE EDITORS}
E. F. BECKENBACH
B. H. NeumanN
F. WOLF
K. YoSHIDA

\section{SUPPORTING INSTITUTIONS}

UNIVERSITY OF BRITISH COLUMBIA

CALIFORNIA INSTITUTE OF TECHNOLOGY

UNIVERSITY OF CALIFORNIA

MONTANA STATE UNIVERSITY

UNIVERSITY OF NEVADA, RENO

NEW MEXICO STATE UNIVERSITY

OREGON STATE UNIVERSITY

UNIVERSITY OF OREGON

OSAKA UNIVERSITY

\author{
UNIVERSITY OF SOUTHERN CALIFORNIA \\ STANFORD UNIVERSITY \\ UNIVERSITY OF HAWAII \\ UNIVERSITY OF TOKYO \\ UNIVERSITY OF UTAH \\ WASHINGTON STATE UNIVERSITY \\ UNIVERSITY OF WASHINGTON \\ $\stackrel{*}{*} \stackrel{*}{*} \stackrel{*}{*}$ AMERICAN MATHEMATICAL SOCIETY
}

The Supporting Institutions listed above contribute to the cost of publication of this Journal, but they are not owners or publishers and have no responsibility for its content or policies.

Mathematical papers intended for publication in the Pacific Jaurnal of Mathematics should be in typed form or offset-reproduced, (not dittoed), double spaced with large margins. Please do not use built up fractions in the text of your manuscript. You may however, use them in the displayed equations. Underline Greek letters in red, German in green, and script in blue. The first paragraph or two must be capable of being used separately as a synopsis of the entire paper. Items of the bibliography should not be cited there unless absolutely necessary, in which case they must be identified by author and Journal, rather than by item number. Manuscripts, in triplicate, may be sent to any one of the editors. Please classify according to the scheme of Math. Reviews, Index to Vol. 39. All other communications should be addressed to the managing editor, or Elaine Barth, University of California, Los Angeles, California, 90024.

The Pacific Journal of Mathematics expects the author's institution to pay page charges, and reserves the right to delay publication for nonpayment of charges in case of financial emergency.

100 reprints are provided free for each article, only if page charges have been substantially paid. Additional copies may be obtained at cost in multiples of 50 .

The Pacific Journal of Mathematics is issued monthly as of January 1966. Regular subscription rate: $\$ 7200$ a year (6 Vols., 12 issues). Special rate: $\$ 36.00$ a year to individual members of supporting institutions.

Subscriptions, orders for back numbers, and changes of address should be sent to Pacific Journal of Mathematics, 103 Highland Boulevard, Berkeley, California, 94708.

PUBLISHED BY PACIFIC JOURNAL OF MATHEMATICS, A NON-PROFIT CORPORATION

Printed at Kokusai Bunken Insatsusha (International Academic Printing Co., Ltd.). 8-8, 3-chome, Takadanobaba, Shinjuku-ku, Tokyo 160, Japan.

Copyright (C) 1975 by Pacific Journal of Mathematics Manufactured and first issued in Japan 


\section{Pacific Journal of Mathematics}

Vol. 72, No. 2

February, 1977

George E. Andrews, Plane partitions. II. The equivalence of the

Bender-Knuth and MacMahon conjectures ................. 283

Lee Wilson Badger, An Ehrenfeucht game for the multivariable quantifiers

of Malitz and some applications ......................... 293

Wayne C. Bell, A decomposition of additive set functions ............ 305

Bruce Blackadar, Infinite tensor products of $C^{*}$-algebras ............. 313

Arne Brøndsted, The inner aperture of a convex set .............. 335

N. Burgoyne, Finite groups with Chevalley-type components........... 341

Richard Dowell Byrd, Justin Thomas Lloyd and Roberto A. Mena, On the retractability of some one-relator groups .....................

Paul Robert Chernoff, Schrödinger and Dirac operators with singular potentials and hyperbolic equations .................... 361

John J. F. Fournier, Sharpness in Young's inequality for convolution ....... 383

Stanley Phillip Franklin and Barbara V. Smith Thomas, On the metrizability

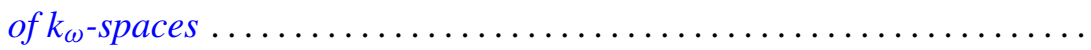

David Andrew Gay, Andrew McDaniel and William Yslas Vélez, Partially normal radical extensions of the rationals .................... 403

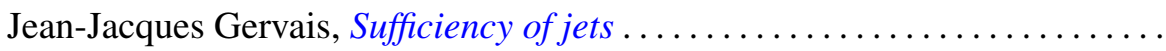

Kenneth R. Goodearl, Completions of regular rings. II . .

Sarah J. Gottlieb, Algebraic automorphisms of algebraic groups with stable maximal tori

Donald Gordon James, Invariant submodules of unimodular Hermitian forms.....

J. Kyle, $W_{\delta}(T)$ is convex.

Ernest A. Michael and Mary Ellen Rudin, A note on Eberlein compacts ...

Ernest A. Michael and Mary Ellen Rudin, Another note on Eberlein compacts ....

Thomas Bourque Muenzenberger and Raymond Earl Smithson, Fixed point theorems for acyclic and dendritic spaces.

Budh Singh Nashier and A. R. Rajwade, Determination of a unique solution of the quadratic partition for primes $p \equiv 1(\bmod 7)$.

Frederick J. Scott, New partial asymptotic stability results for nonlinear ordinary differential equations ....................

Frank Servedio, Affine open orbits, reductive isotropy groups, and dominant gradient morphisms; a theorem of Mikio Sato..........

D. Suryanarayana, On the distribution of some generalized square-full integers.................................. 